\title{
Phenolic profile and antioxidant activity in apple juice and pomace: effects of different storage conditions
}

\author{
Esther Maragò ${ }^{1}$, Patrizia Iacopini ${ }^{1}$, Fabiano Camangi $^{1}$, Claudia Scattino ${ }^{2}$, Annamaria Ranieri $^{2}$, \\ Agostino Stefani ${ }^{1}$ and Luca Sebastiani ${ }^{1, \star}$ \\ 1 BioLabs, Istituto di Scienze della Vita, Scuola Superiore Sant'Anna, Piazza Martiri della Libertà 33, 56127, Pisa, Italy \\ 2 Dipartimento di Scienze Agrarie, Alimentari e Agro-ambientali, Università degli Studi di Pisa, Pisa, Italy
}

Received 28 June 2014 - Accepted 24 February 2015

\begin{abstract}
Introduction. Apples have been part of the human diet since ancient times and are one of the most commonly consumed fruit worldwide, rich in phenolic compounds. Phenolics are naturally occurring non-nutritive plant compounds, possessing several health benefits. The effect of storage conditions on phenolics concentrations and on the antioxidant activity of apple juice and pomace was studied. Materials and Methods. Experiments were carried out with two apple varieties, an ancient Tuscan variety, Panaia-red, and a commercial variety, Golden Delicious. The antioxidant activity was assessed by means of two different in vitro tests: scavenging of DPPH• radical, and inhibition of tyrosine nitration mediated by peroxynitrite $\left(\mathrm{ONOO}^{-}\right)$. Analyses of juices were carried out immediately after production and after 2 weeks storage in 3 different temperature conditions: $4{ }^{\circ} \mathrm{C},-20^{\circ} \mathrm{C}$ and room temperature after pasteurisation. Results and discussion. Highly significant differences were recorded between the two varieties, the Panaia-red juice having a higher concentration of phenolic compounds and a higher antioxidant activity. During apple juice storage, phenolic compound concentrations and antioxidant capacity remained quite stable. A correlation between antioxidant activity and phenolic concentration was observed $(0.69 \leqslant r \leqslant 0.97)$. Conclusion. The effects of a short storage time and different conditions of storage on the phenolic concentration and antioxidant activity seem to be less relevant than variety effects. The apple pomace revealed an amount of phenolic compounds, ranging from 6.8 to $15.5 \mathrm{mg}$ GAE $100 \mathrm{~g}^{-1} \mathrm{DM}$ of total polyphenols, which paves the way for their use as ingredients in foods lacking in polyphenols.
\end{abstract}

Keywords: Italy / apple / Malus domestica / DPPH• radical / phenolics / shelf-life / tyrosine nitration

Résumé - Profil phénolique et activité anti-oxydante du jus et du marc de pomme : effets des conditions de stockage. Introduction. Depuis la plus haute Antiquité, les pommes ont fait partie de l'alimentation humaine et constituent l'un des fruits les plus consommés au monde, et riches en composés phénoliques. Les composés phénoliques sont des composés végétaux naturels non nutritifs mais possédant de nombreuses propriétés nutritionnelles bénéfiques pour la santé. L'étude porte sur l'effet des conditions de stockage sur la concentration de ces composés phénoliques et sur l'activité anti-oxydante du jus de pomme et du marc. Matériel et méthodes. Les expériences ont été réalisées avec deux variétés de pomme, une variété ancienne toscane, Panaia-rouge, et une variété commerciale, Golden Delicious. L'activité anti-oxydante a été évaluée au moyen de deux tests in vitro : la réactivité avec le radical libre DPPH•, et l'inhibition de la nitration de la tyrosine induite par le peroxynitrite $\left(\mathrm{ONOO}^{-}\right)$. Les analyses de jus ont été effectuées immédiatement après production et après 2 semaines de stockage à températures différentes : $+4{ }^{\circ} \mathrm{C},-20{ }^{\circ} \mathrm{C}$, ou à température ambiante après pasteurisation. Résultats et discussion. Des différences hautement significatives ont été enregistrées entre les deux variétés, le jus des pommes Panaia-rouge ayant une concentration en composés phénoliques plus élevée et une activité anti-oxydante supérieure à celui des Golden Delicious. Au cours du stockage des jus, la concentration en composés phénoliques et la capacité anti-oxydante sont restées stables. Une corrélation entre la concentration phénolique et l'activité anti-oxydante a été observée $(0,69 \leqslant r \leqslant 0,97)$. Conclusion. Apparemment, un stockage de courte durée et diverses conditions de conservation ont eu moins d'effet sur la concentration phénolique et l'activité anti-oxydante des jus de pomme que l'origine variétale des fruits. Le marc de pomme a révélé une quantité de composés phénoliques allant de 6,8 à 15,5 mg GAE $100 \mathrm{~g}^{-1}$ MS de polyphénols totaux, ce qui ouvre la voie à leur utilisation comme ingrédients dans les aliments dépourvus de polyphénols.

Mots clés : Italie / pommier / Malus domestica / radical libre DPPH•/ composés phénoliques / nitration de la tyrosine / aptitude à la conservation

\footnotetext{
^ Corresponding author: luca.sebastiani@sssup.it
} 


\begin{abstract}
Abbreviations: 3-NT, 3-nitrotyrosine; CE, catechin equivalent ; DM, dry matter; DPPH•, 1,1-diphenyl-2picrylhydrazyl ; F3Os, flavan-3-ols ; FW, fresh weight ; GAE, gallic acid equivalent ; LDL, low-density lipoprotein ; $\mathrm{ONOO}^{-}$, peroxynitrite ; RT, room temperature ; TAE, tartaric acid equivalent ; TF, total flavonoids ; TP, total phenols.
\end{abstract}

\section{Introduction}

Phenolic compounds are naturally occurring non-nutritive plant compounds and they constitute one of the most abundant and widely distributed groups of substances in the plant kingdom. They are commonly divided into two groups: flavonoids (anthocyanins, flavan-3-ols, flavonols, flavones, isoflavones, flavanones), and non-flavonoid compounds (hydroxybenzoic and hydroxycinnamic acids, stilbenes).

Despite their wide distribution in plants, nutritional interest in their health-protecting factor is a recent phenomenon. This beneficial effect is mainly associated with the antioxidant activity of phenolic compounds, acting as reducing agents by donating hydrogen, quenching singlet oxygen, acting as chelators and trapping free radicals. These highly reactive molecules are present in biological systems and may oxidise nucleic acids, proteins and lipids, promoting degenerative diseases such as cancer, heart disease, dermal disorders and ageing [1-4]. Fruit is one of the most important sources of antioxidants such as vitamins (especially vitamin $\mathrm{C}$ and vitamin $\mathrm{E}$ ) and bioactive phytochemicals (polyphenols and carotenoids) [5] .

Apples have been part of the human diet since ancient times and are one of the most commonly consumed fruit worldwide. They are eaten both raw and in processed products, such as juice, cider, brandy jam and vinegar, and they represent a very significant source of phenolic compounds, particularly flavonoids. Every family of phenols is directly responsible for the special characteristics of specific apple varieties, apple derivatives and by-products, such as apple pomace [6]. There are five major groups of phenolic compounds in apples: hydroxycinnamic acids, flavan-3-ols, anthocyanins, flavonols and dihydrochalcones. However, the phenolic profile of apples is much more complicated due to polymerisation of flavan-3-ols, as these compounds can be found as monomers, dimers and polymers (procyanidins) and glycosylation of other compounds, such as flavonols [7]. Many factors, such as genetic, agronomic and environmental ones, influence the complexity of the phytochemical profile of apples and these variations predispose the differences in apple antioxidant activity [7-9]. Moreover, it is important to take into consideration the bioavailability and the bioactivity of an antioxidant compound in the human body, and not only the amount introduced by the diet [10].

The main source of polyphenols from apple is represented by fresh fruit consumption. The most popular processed apple product in the world, clear apple juice, has a lower phenolic content because, during production, only part of the compounds are extracted in the apple juice [11] and the rest remain in the pomace [12]. It was demonstrated that the consumption of cloudy apple juice may be more beneficial to human health than clear apple juice, due to its higher content of phenolic compounds and fibres [13-15].The loss of phenolic compounds during juice production is also due to the enzymatic oxidation of phenolics catalysed by polyphenol oxidase (PPO) in the presence of oxygen. PPO is present mainly in apple flesh, bound to the cell walls, whereas phenolic compounds are located in vacuoles [16]. During apple tissue disintegration the enzyme is released from cell walls and can catalyse the oxidation of phenolic compounds to corresponding o-quinones which easily condense to brown pigments. According to the data of van der Sluis et al. [12], some juices maintained only $3-10 \%$ of the antioxidant activity of the fresh fruit [17], as the antioxidant activity of juices is positively correlated with the content of phenolics $[18,19]$.

However, fruit juice consumption overall in Europe, Japan, Australia, New Zealand and the USA has increased in recent years, probably due to public perception of juices as a natural source of healthy antioxidant phytochemicals and increased public interest in health issues. Especially for apple juice, it was demonstrated that their antioxidant activity can be accounted for essentially by chlorogenic acid and other compounds in lower concentrations, such as phloridzin and epicatechin [20,21]. Therefore, fruit juice intake has been consistently associated with reduced risk of many cancer types and may also protect against stroke and delay the onset of Alzheimer's disease [22-25].

Apple pomace is a by-product in apple juice production, consisting of peel, core, seed, calyx, stem and soft tissue, representing around $25-30 \%$ of the fresh fruit weight [26]. A large quantity of apple pomace is produced worldwide every year and its disposal has caused a serious environmental problem. Researchers have proposed the use of apple pomace for the production of different value-added products including enzymes, organic acids, ethanol, aroma compounds and natural antioxidants [27]. The antioxidant compounds from waste products of the food industry could be used to increase the stability of foods by preventing lipid peroxidation, and also for protecting living systems from oxidative damage by scavenging oxygen free radicals [28].

In order to satisfy the growing demand for products with a high content of bioactive molecules, it is essential to understand the influence of the different phases of the food production chain on the presence of these compounds in the product. Cultivation methods, choice of raw material, industrial processing, storage, distribution and final processing by the consumer may all affect the final concentrations and the bioactivity of the product. This knowledge will provide the food processing industry with means that can be used in product optimisation with respect to health-protecting compounds, without affecting traditional quality aspects, such as colour and taste [29].

Within this context, the main purpose of this research was to investigate whether the level of phenolics and in vitro antioxidant activity in apple juice and its by-product (pomace) were affected by the juice production chain. Comparisons between two apple varieties and among different storage 
conditions were performed in order to evaluate the stability of the phenolic composition and the maintenance of the antioxidant activity two weeks after production of apple juice.

\section{Materials and methods}

\subsection{Chemicals}

Gallic acid, catechin, epicatechin, chlorogenic acid, phloretin, phloridzin, quercetin-3-galactoside, Trolox, FolinCiocalteu reagent, tyrosine, 3-nitrotyrosine, 1,1-DiPhenyl2-PicrylHydrazyl (DPPH• 90\%), 4-(dimethylamino)cinnamaldehyde (DMACA) and HPLC-grade methanol were purchased from Sigma Aldrich (Milan, Italy). All chemicals were of analytical or HPLC grade and the aqueous solutions were prepared by using ultra-pure water purified by the Milli-Q System (Millipore, Milan, Italy).

\subsection{Fruit materials}

The Malus $\times$ domestica Borkh genotypes used in this study were a commercial variety (Golden Delicious) and an old local variety (Panaia-red). Panaia-red is an ancient Tuscan variety [30] known and cultivated especially in the Casentino area [31]. This local variety has been catalogued and described in the regional repertories of Tuscany (http://germoplasma. arsia.toscana.it/Germo/), which represent the basic tool of the protection system for regional autochthonous genetic resources, and actions are in progress for the valorisation of this variety [32].

The study was carried out in 2008 in the Casentino area (Tuscany, Italy) and apples were collected at commercial maturity. The optimal harvest period was from 25th to 30th September for Golden Delicious and from 20th to 30th October for Panaia-red. Three replicates of each variety were collected. Each replicate was made up of 4 apples, randomly sampled from a bulk of independent harvests of $10 \mathrm{~kg}$ apples each.

\subsection{Preparation of apple juice and pomace}

After harvest, apples were washed and cut into pieces. Apple juice was prepared using a domestic centrifuge for the production of fruit and vegetable juices (Vita Pro-Active, mod. JE810, Kenwood Ltd., Havant, UK). The operations were carried out at $4{ }^{\circ} \mathrm{C}$. The juice obtained from the two varieties was divided into three groups of $12 \mathrm{~mL}$-aliquots. Each group of aliquots underwent different methods of storage: $4{ }^{\circ} \mathrm{C}$ and $-20^{\circ} \mathrm{C}$ and room temperature after pasteurisation at $68^{\circ} \mathrm{C}$ for $30 \mathrm{~min}$. Analyses were performed on juices immediately after the production and after two weeks of storage. Apple juices were filtered prior to analysis.

An aliquot of the apple pomace, the by-product of the apple juice production, was also recovered, stored at $-20^{\circ} \mathrm{C}$ and subsequently freeze-dried (Edwards Mini-Fast 1770, Edwards Alto Vuoto, Milan, Italy).

\subsection{Apple pomace phenolic extraction}

An aliquot of $200 \mathrm{mg}$ powdered freeze-dried apple pomace was extracted with $80 \%$ methanol for $30 \mathrm{~min}$ in the dark. The extracts were centrifuged for $15 \mathrm{~min}$ at 3,300 rpm $(2,500 \mathrm{~g})$, using a Sigma $302 \mathrm{~K}$ Centrifuge from Bicasa (Milan, Italy), with a swing-out rotor. The precipitate was extracted again with the same solvent and made up to a final volume of $90 \mathrm{~mL}$. The solvent was evaporated with a rotary evaporator and the precipitate was taken up in $12 \mathrm{~mL}$ methanol. Extracts were stored at $-20{ }^{\circ} \mathrm{C}$ and analysed within a month after extraction.

\subsection{Physico-chemical parameter determination}

Soluble solids content (SSC) and titratable acidity (TA) were measured in the apple juice. SSC was determined with a hand-held refractometer (Sper Scientific, AZ, USA), and results expressed as ${ }^{\circ}$ Brix. TA was determined by titrating $10 \mathrm{~mL}$ of juice with $0.1 \mathrm{~N} \mathrm{NaOH}$ to $\mathrm{pH} 8.1$ using $1 \%$ phenolphthalein, and results were expressed as malic acid equivalents (MAE) $\mathrm{L}^{-1}$ juice.

\subsection{Total phenolics, flavonoids and flavan-3-ols}

Total phenolic concentration (TP) was measured by the method described by Singleton and Rossi [33], with some modifications to reduce volumes. TP concentration was expressed as mg gallic acid equivalents (GAE) $100 \mathrm{~g}^{-1}$ dry matter (DM) or mg GAE L ${ }^{-1}$ juice.

Total flavonoids concentration (TF) was determined using a colorimetric assay [34]. TF concentration was expressed as mg catechin equivalents (CE) $100 \mathrm{~g}^{-1} \mathrm{DM}$ or $\mathrm{mg} \mathrm{CE} \mathrm{L}^{-1}$ juice.

Flavan-3-ols (F3Os) were determined using the method described by Nagel and Glories [35]. F3O concentration was expressed as mg catechin equivalents (CE) $100 \mathrm{~g}^{-1} \mathrm{DM}$ or $\mathrm{mg}$ $\mathrm{CE} \mathrm{L}^{-1}$ juice.

\subsection{HPLC for phenolic composition}

High-performance liquid chromatography (HPLC) was performed on apple juices immediately after preparation (T0) and after two weeks storage (T2) at $4{ }^{\circ} \mathrm{C},-20^{\circ} \mathrm{C}$ and at room temperature after pasteurisation using a Spectra System $\mathrm{P} 4000$ HPLC, equipped with a UV 6000 LP photodiode array detector (Thermo Fisher Scientific, Waltham, MA). The column $(250 \times 4.60 \mathrm{~mm}, 5 \mu \mathrm{m})$ was a Phenomenex Prodigy LC-18 RP. The mobile phase flow rate was fixed at $1.0 \mathrm{~mL} \mathrm{~min}^{-1}$. For the gradient elution $\mathrm{H}_{2} \mathrm{O}$, pH 2.7 (with formic acid) (A), and methanol (B) were used as mobile phases: $0 \mathrm{~min}, 90 \% \mathrm{~A}, 10 \%$ B; 5 min, $90 \%$ A, $10 \%$ B; 20 min, $70 \%$ A, $30 \%$ B; 28 min, $10 \%$ A, $90 \%$ B; 35 min, $90 \%$ A, $10 \%$ B. The detection was at $280 \mathrm{~nm}, 320 \mathrm{~nm}$ and $350 \mathrm{~nm}$. Identification and quantification were carried out using external standards. 


\subsection{Synthesis of peroxynitrite and inhibition of tyrosine nitration}

Peroxynitrite was synthesised according to the method used by Beckman et al. [36] as described in Iacopini et al. [37]. Inhibition of tyrosine nitration is based on the determination of the 3-NT quantity formed from the reaction between free tyrosine and peroxynitrite at the physiological $\mathrm{pH}$ by reversedphase HPLC-UV analysis, as described elsewhere [37]. The HPLC system consisted of a Dionex P 680 Pump coupled with a Dionex UVD 170U/340U UV/VIS detector. Data processing was performed by using the software Chromeleon 6.5 (Dionex) running on a PC coupled with the HPLC system. Separation was performed on a reverse-phase C18 column (Acclaim 120, $5 \mu \mathrm{m}, 4.6 \times 250 \mathrm{~mm}$, Dionex) coupled with a C 18 guard cartridge (Acclaim 120, $5 \mu \mathrm{m}, 4.3 \times 10 \mathrm{~mm}$, Dionex) at room temperature. Samples were injected into the HPLC system after filtering through a $0.45-\mu$ m cellulose filter (Millipore).

Elution conditions for the detection of 3-NT were as follows: $20 \mathrm{mM}$ phosphate buffer ( $\mathrm{pH} 3.2$ )/methanol 92:8; flow rate $1 \mathrm{~mL} \mathrm{~min}{ }^{-1}$ in isocratic mode; $20 \mu \mathrm{L}$ injection volume; UV detection at $356 \mathrm{~nm}$.

Quantitative determination of the 3-NT formed was performed by HPLC-UV using an external standard calibration curve $\left(\mathrm{Abs}_{356}=54.717 \times[3-\mathrm{NT}]-0.224, r^{2}=0.999\right)$. The peroxynitrite scavenging ability of the extracts was expressed as Trolox Equivalents (TE) $100 \mathrm{~g}^{-1} \mathrm{DM}$ or TE $\mathrm{L}^{-1}$ juice.

\subsection{Antioxidant activity: DPPH• radical scavenging capacity}

This method was performed using 1,1-diphenyl-2picrylhydrazyl radical (DPPH•) [38]. Briefly, an aliquot of $0.1 \mathrm{~mL}$ of an appropriate dilution of each apple extract and juice was added to $3.9 \mathrm{~mL}$ DPPH• methanolic solution $\left(1210^{-5} \mathrm{M}\right)$, and vortexed. Absorbance at $515 \mathrm{~nm}\left(\mathrm{~A}_{515}\right)$ was measured at different time intervals on a UV-VIS Agilent HP 8453 diode array spectrophotometer until the reaction reached a plateau. The initial concentration of DPPH• was controlled for every experiment by using a calibration curve made by measuring the absorbance at $515 \mathrm{~nm}$ of standard samples of $\mathrm{DPPH}$ at different concentrations. The equation of the curve was $\mathrm{Abs}_{515}=0.0085 \times[\mathrm{DPPH} \bullet]\left(r^{2}=0.99810\right)$, as determined by linear regression. The DPPH• radical scavenging effect was expressed as percentage reduction $(\% \mathrm{R})$ of the initial $\mathrm{DPPH} \bullet$ absorption operated by test samples:

$\% \mathrm{R}$ of the initial DPPH $\bullet$ absorption $=$

$$
\left[\left(A_{\mathrm{DPPH}}\left(t_{0}\right)-A_{\text {sample }}(t)\right) / A_{\mathrm{DPPH}}\left(t_{0}\right)\right] \times 100
$$

where $A_{\mathrm{DPPH}}\left(t_{0}\right)$ is the absorbance of $\mathrm{DPPH} \bullet$ at zero time and $A_{\text {sample }}(t)$ is the absorbance of the solution added to the sample after $t$ time.

The DPPH• scavenging capacity was evaluated through the analysis of the logarithmic curves obtained by measuring the radical percentage reduction after 5, 20, 40, 60, 90 and $120 \mathrm{~min}$ of reaction, and a statistical determination was also applied to the single values achieved after $120 \mathrm{~min}$ of reaction.

\subsection{Statistics}

Three analytical determinations were carried out on each independent biological replication for every parameter. Three independent biological replications $(n=3)$ were obtained from each treatment and the results presented in tables and graphs are reported as means \pm standard deviation (SD). Statistical differences in phenolic concentration and antiradical activity among varieties were determined by $t$-test. The storage temperature, cultivar effect and interaction between them were evaluated by means of two-way ANOVA, in this case followed by a post-hoc comparison test (Tukey's HSD) at $P \leqslant 0.05$. Non-linear regression analysis between the percentage of inhibition of DPPH• during the 120 min of reaction was done for each sample $(n=3)$ using a logarithmic function (percentage of inhibition of DPPH $\bullet=\mathrm{a} \times \ln (t)+\mathrm{b})$. Statistical differences determined by Cultivar, Temperature and Cultivar $\times$ Temperature interaction in $\mathrm{a}$ and $\mathrm{b}$ regression coefficients were assessed by ANOVA. Linear regressions between phenolic concentration and antioxidant activity of Panaia-red and Golden Delicious apple juices were done and correlation coefficients and $P$-values were determined.

\section{Results and discussion}

\subsection{Juice production and physicochemical parameters}

In this study we investigated the phenolic profile and antioxidant capacity of the juice obtained from two apple cultivars grown in Tuscany and of the pomace obtained as a byproduct of the juice production.

The juice yield was around 26\% for Panaia-red and $48 \%$ for Golden Delicious, strongly affected by the cultivar. However, other parameters such as maturity, storage conditions and the apple juice production method can be relevant, as reported by others [19]. Immediately after production, SSC, $\mathrm{pH}$ and TA of juices were determined, as these quality parameters are related to the stability of bioactive compounds in plant-derived products (table I). The two juice samples did not show any statistically significant difference as regards $\mathrm{pH}$ $(3.6 \pm 0.1$ and $3.8 \pm 0.1$ units for Panaia-red and Golden Delicious, respectively) or SSC $(15.1 \pm 0.1$ and $15.3 \pm 2.2$ for Panaia-red and Golden Delicious, respectively). Regarding TA content, Panaia-red juice had twice the amount of Golden Delicious, the values being $9.3 \pm 1.2 \mathrm{MAE} \mathrm{L}^{-1}$ for Panaia-red and $4.6 \pm 0.4 \mathrm{MAE} \mathrm{L}^{-1}$ for Golden Delicious (table I). As regards the apple pomace, the $\%$ of dry matter content was $20.4 \pm 1.6 \%$ for Panaia-red and $21.4 \pm 2.2 \%$ for Golden Delicious.

Following two weeks storage in different temperature conditions $\left(+4{ }^{\circ} \mathrm{C},-20^{\circ} \mathrm{C}\right.$ and $\mathrm{RT}$ after pasteurisation) the parameters were determined again. Concerning TA content, Panaiared juice had twice the amount of Golden Delicious, as in the juices after preparation. Storage conditions did not affect SSC and TA of Golden Delicious and Panaia-red apple juice ( $t a-$ ble I). A significant influence was, however, recorded when $\mathrm{pH}$ was considered. In fact, a significant $\mathrm{pH}$ reduction was found in Panaia-red juice samples stored at $-20{ }^{\circ} \mathrm{C}(3.5 \pm 0.2$ at $+4{ }^{\circ} \mathrm{C}, 3.2 \pm 0.2$ at $-20^{\circ} \mathrm{C}$ and $3.5 \pm 0.3$ at RT after pasteurisation) and in Golden Delicious juice samples stored at 
Table I. Physicochemical parameters of Golden Delicious and Panaia-red apple juices after production and after 2 weeks storage at $+4{ }^{\circ} \mathrm{C}$, $-20{ }^{\circ} \mathrm{C}$ or at room temperature after pasteurisation (RT). Values are the means $\pm \operatorname{SD}(n=3)$. Data were analysed by $t$-test for apple juice after preparation and by ANOVA for apple juice after 2 weeks storage.

\begin{tabular}{lccc}
\hline & SSC & TA & $\mathrm{pH}$ \\
& $\left({ }^{\circ} \mathrm{Brix}\right)$ & $\left(\mathrm{MAE} \mathrm{L}^{-1}\right)$ & $($ Units $)$ \\
\hline Apple juice after preparation & & & \\
Golden Delicious & $15.3 \pm 2.2$ & $4.6 \pm 0.4$ & $3.8 \pm 0.1$ \\
Panaia-red & $15.1 \pm 0.1$ & $9.3 \pm 1.2$ & $3.6 \pm 0.1$ \\
\hline$P$ values & $\mathrm{ns}$ & $* * *$ & $\mathrm{~ns}$ \\
\hline Apple juice after 2 weeks storage & & & \\
Golden Delicious $+4{ }^{\circ} \mathrm{C}$ & $15.7 \pm 1.5$ & $4.2 \pm 0.4$ & $3.3 \pm 0.0$ \\
Golden Delicious $-20{ }^{\circ} \mathrm{C}$ & $15.3 \pm 1.6$ & $4.4 \pm 0.5$ & $3.3 \pm 0.1$ \\
Golden Delicious $\mathrm{RT}^{\mathrm{a}}$ & $16.1 \pm 1.9$ & $4.8 \pm 0.4$ & $3.5 \pm 0.1$ \\
Panaia-red $+4{ }^{\circ} \mathrm{C}$ & $14.9 \pm 0.8$ & $9.1 \pm 0.8$ & $3.5 \pm 0.2$ \\
Panaia-red $-20{ }^{\circ} \mathrm{C}$ & $15.1 \pm 0.1$ & $8.9 \pm 1.1$ & $3.2 \pm 0.2$ \\
Panaia-red RT & $15.1 \pm 0.3$ & $8.4 \pm 1.3$ & $3.5 \pm 0.3$ \\
\hline$P$ ANOVA & & & \\
Cultivar & $\mathrm{ns}$ & $* * *$ & $\mathrm{~ns}$ \\
Temperature & $\mathrm{ns}$ & $\mathrm{ns}$ & $* * *$ \\
Cultivar $\times$ Temperature & $\mathrm{ns}$ & $\mathrm{ns}$ & $\mathrm{ns}$ \\
\hline
\end{tabular}

${ }^{\text {a }}$ Room temperature after pasteurisation.

${ }^{\mathrm{b}}$ Mean differences significant at $* * * P<0.001$; ns: not significant.
$+4{ }^{\circ} \mathrm{C}$ and $-20{ }^{\circ} \mathrm{C}\left(3.3 \pm 0.0\right.$ at $+4{ }^{\circ} \mathrm{C}, 3.3 \pm 0.1$ at $-20^{\circ} \mathrm{C}$ and $3.5 \pm 0.1$ at RT after pasteurisation). Aguilar-Rosas et al. [26] found that $\mathrm{pH}$ was affected by thermal treatments in apple juice, the untreated sample having a higher value. In our work, the juices stored for two weeks at $+4{ }^{\circ} \mathrm{C}$ and $-20{ }^{\circ} \mathrm{C}$ seemed to be the most affected.

As acidity in apple juice has to be considered an important sensory attribute associated with its characteristics of flavour and astringency, maintenance of the original characteristics is desirable. Thermal treatment did not have an effect on apple juice titratable acidity, in agreement with other authors [39], while in orange juice significant differences were observed between freshly squeezed and commercial (pasteurised and frozen without previous pasteurisation) juices analysed in the middle of their commercial shelf life [40].

\subsection{Apple juice and pomace phenolic concentration}

Genotype-related differences in phenolic levels between Panaia-red and Golden Delicious were very evident both in juices and in pomaces (table II). In apple pomace (table II), phenolic concentrations were very high, suggesting a potential for commercial exploitation. This was particularly evident for the Panaia-red by-product, which contained about a 1.3, 1.9 and 1.9 times higher concentration of TP, TF and F3Os than Golden Delicious, respectively (table II). The range of concentrations of phenolic classes determined in Panaia-red and Golden Delicious pomace was generally consistent with previous reports in the literature, even if referring to different cultivars [6,41,42]. Ćetković et al. [41] reported a lower amount of $\mathrm{TF}$ in their apple pomace samples, as they reported values between $0.45 \pm 0.02$ and $1.19 \pm 0.06 \mathrm{mg} \mathrm{g}^{-1} \mathrm{DM}$, while we found $11.0 \pm 3.1$ and $3.8 \pm 0.6 \mathrm{mg} \mathrm{g}^{-1} \mathrm{DM}$, respectively, for Panaiared and Golden Delicious pomace. The dry matter contents of the two varieties' pomace were not significantly different and constituted $20.4 \%$ and $21.4 \%$, respectively, for Panaia-red and Golden Delicious.

The same statistically significant difference between the two apple cultivars was also found when the juices were analysed, both immediately after production (table II) and after 2 weeks storage in different temperature conditions (table II). Panaia-red juice had a higher phenolic concentration than Golden Delicious: 3.4, 7.2 and 6.5 times higher for TP, TF and F3Os, respectively. No statistically significant difference was found when the effect of storage temperature was considered (table II), showing that such a short storage time is not enough to produce a significant phenolic reduction, even when the juices are maintained at $+4{ }^{\circ} \mathrm{C}$. Similar results were also observed by other authors [29], who reported that 1 month storage of apple juice in a refrigerator at $+4{ }^{\circ} \mathrm{C}$, or even at room temperature had no effect on lowering the concentration of phenolic antioxidants. No statistically significant interaction was found between the cultivar and storage temperature.

A different scenario can be envisaged when the percentage ratio of the TP, TF and F3Os of the juices after 2 weeks storage with respect to the time of preparation is determined within each cultivar separately (figure $1 A-1 B$ ). A temperature effect appears evident. As regards Golden Delicious, the pasteurised juice has a higher TP concentration than those stored at $+4{ }^{\circ} \mathrm{C}$ and $-20{ }^{\circ} \mathrm{C}$, and statistically significant differences were recorded for $\mathrm{TF}$ and $\mathrm{F} 3 \mathrm{Os}$ in all three storage conditions with the following order: pasteurised $>-20{ }^{\circ} \mathrm{C}>+4{ }^{\circ} \mathrm{C}$. No statistical differences were found for Panaia-red juice TP, though the pasteurised sample had a higher concentration of $\mathrm{TF}$ than the samples stored at +4 and $-20^{\circ} \mathrm{C}$. The $\mathrm{F} 3 \mathrm{O}$ concentration of Panaia-red juice was significantly influenced by storage conditions in the same manner as Golden Delicious. The higher amount of phenolic compounds in pasteurised 
Table II. Total phenols, flavonoids and flavan-3-ols concentrations of apple pomace, apple juice after production, and apple juice after 2 weeks storage at $+4{ }^{\circ} \mathrm{C},-20{ }^{\circ} \mathrm{C}$ or at room temperature after pasteurisation (RT). Values are the means $\pm \operatorname{SD}(n=3)$. Data were analysed by $t$-test for apple juice after preparation and by ANOVA for apple juice after 2 weeks storage.

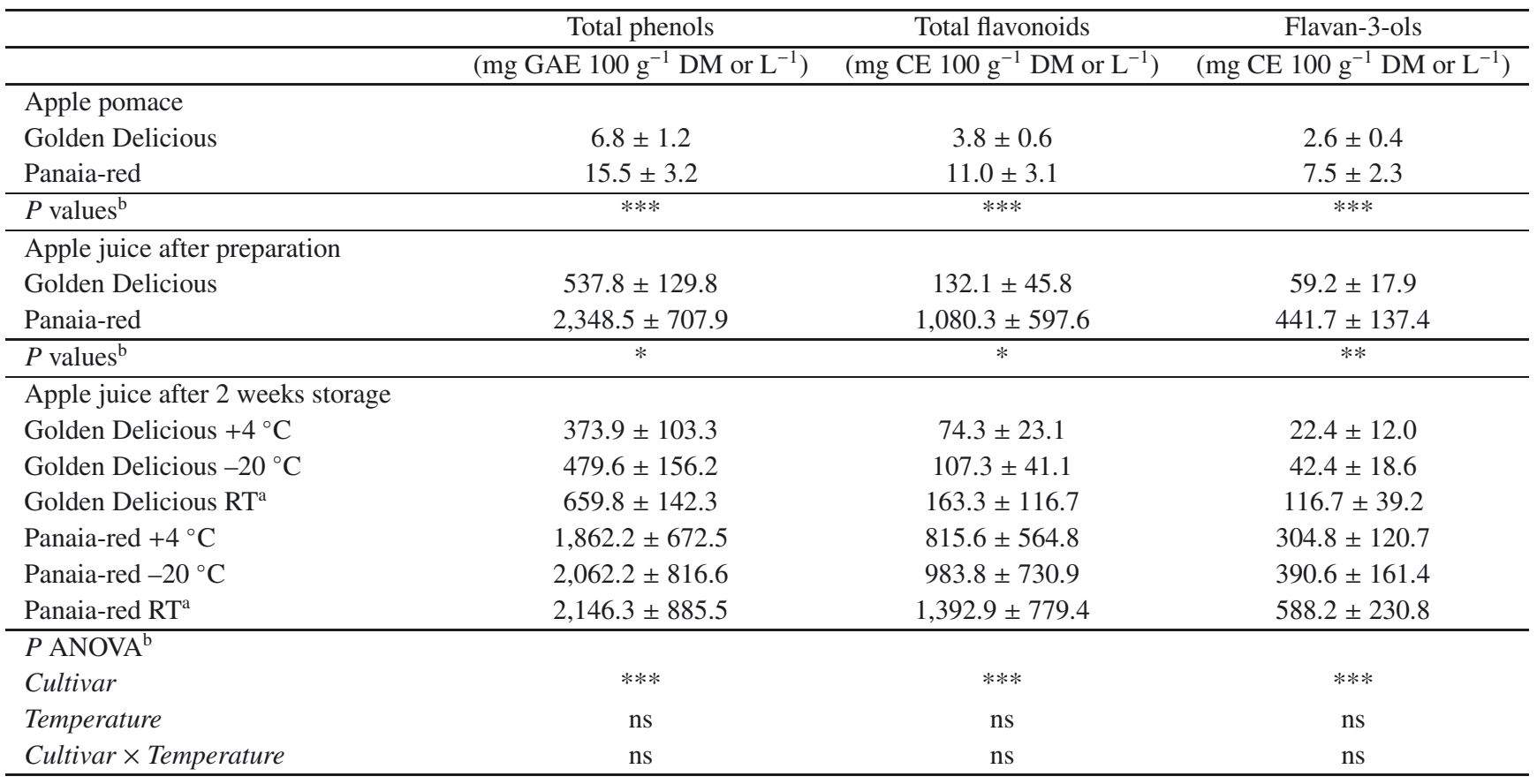

${ }^{\text {a }}$ Room temperature after pasteurisation.

${ }^{\mathrm{b}}$ Mean differences significant at $* P \leqslant 0.05, * * P \leqslant 0.01, * * * P \leqslant 0.001$; ns: not significant.

juices can be explained as a consequence of an enhanced extraction of these compounds from the solid particles of the juice residues and of possible depolymerisation of complex structures in simpler compounds (catechin and epicatechin monomers). However, even the denaturation of PPO enzymes can explain the higher amount of phenolic compounds in pasteurised juices [43].

The results presented in this work are in accordance with those reported in previous work [37] where phenolic compounds in the whole fruit were found to be highly concentrated in Panaia-red as compared with Golden Delicious.

Even considering the lower juice yield in Panaia-red than in Golden Delicious (26\% vs. $48 \%$ ) the total amount of TP compounds recovered in the apple juice was higher for Panaiared than for Golden Delicious. In fact, the amount of TP present in the whole fruit extract (peel+pulp), measured by Iacopini et al. [37], was $221 \pm 28$ and $104 \pm 11 \mathrm{mg}$ GAE $100 \mathrm{~g}^{-1} \mathrm{FW}$ for Panaia-red and Golden Delicious, respectively; the TP recovered in the juice can be estimated at around $28 \%(62 \mathrm{mg}$ ) and 25\% (26 mg), respectively, for Panaia-red and Golden Delicious. The recovery of the flavonoids fraction was lower: $20.3 \%$ for Panaia-red juice and $9.7 \%$ for Golden Delicious juice. Other authors reported that when processing apples into apple juice, the result is a low flavonoid-content juice. In commercially available apple juice, only $2.5 \mathrm{mg} \mathrm{L}^{-1}$ quercetin was detected [44], while in apples the concentration was $36 \pm 19 \mathrm{mg} \mathrm{kg}^{-1}$ analysed as aglycon [45].

\subsection{Apple juice and pomace antioxidant activity}

The antioxidant activity of apple juice and pomace was studied using two in vitro models in order to measure the activities towards different radicals (table III). In particular, apple juice and pomace scavenging ability was measured towards the stable, synthetic radical (DPPH•) and a physiological anion $\left(\mathrm{ONOO}^{-}\right)$able to form, in physiological conditions, two radicals strictly involved in various cellular damage processes, including tyrosine nitration. This mechanism is considered more representative of human physiological conditions than other antiradical assays [36].

As reported elsewhere [11,12], during processing of apples into juice in a conventional way the largest amount of phenolic compounds remained in the pomace and only $3-10 \%$ of the antioxidant activity present in fresh apples was found in the juice. The capacity to inhibit tyrosine nitration present in Golden Delicious and Panaia-red apple juices immediately after production was, respectively, around $18.6 \%$ and $27.8 \%$ that of the fresh fruits, this latter previously measured by Iacopini et al. [37], and considerably higher than values reported by van der Sluis [29].

As regards the apple pomace, the analysis of the coefficients $a$ and $b$ of the logarithmic curves obtained by measuring the radical percentage reduction after 5, 20, 40, 60, 90 and 120 min of reaction (table III) reveals that although both the apple pomaces were significantly active as antioxidant agents, there was a significant difference in the antioxidant behaviour. 
A

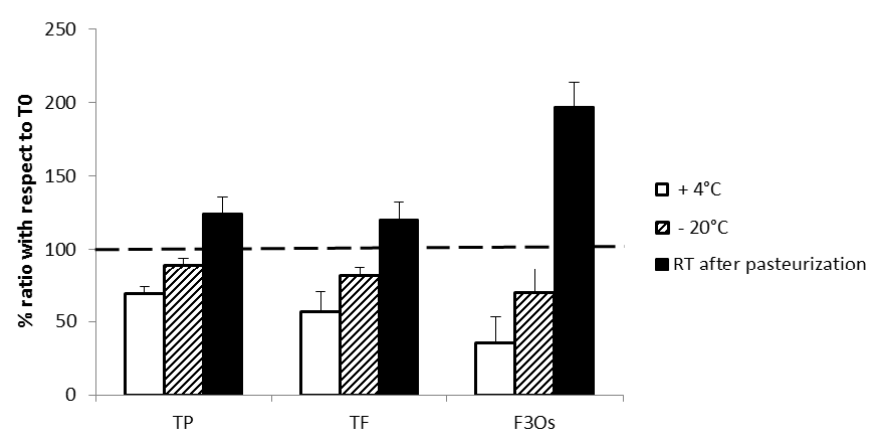

B

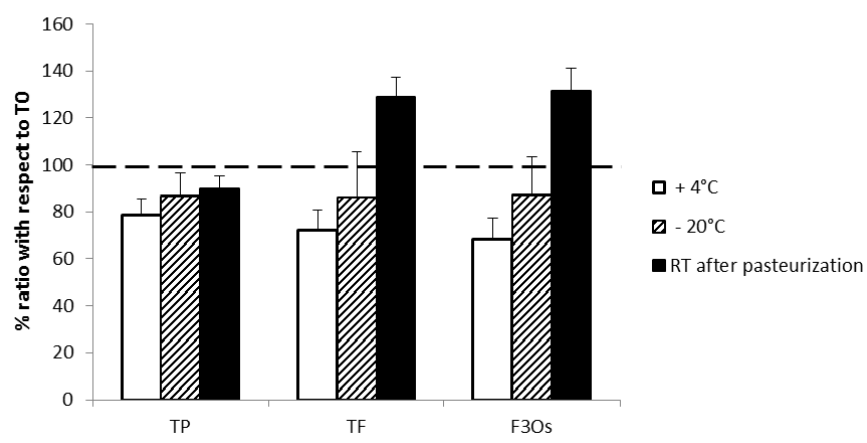

Figure 1. Percentage ratio of total polyphenols (TP), total flavonoids (TF) and flavan-3-ols (F3Os) of Golden Delicious juice (A) and Panaia-red juice (B) after 2 weeks storage with respect to the time of preparation (RT: room temperature). Histograms represent the means and bars the $\operatorname{SD}(n=3)$.

The Panaia-red pomace was statistically more active than the Golden Delicious sample and it operated a faster radical reduction in the first section of the curve, particularly in the first $20 \mathrm{~min}$. Moreover, after $120 \mathrm{~min}$ of reaction, the reduction carried out by the Panaia-red pomace on the DPPH• radical was $56 \%$ higher than that produced by the Golden Delicious pomace (table III). Similar results were found when the two pomace samples were subjected to the $\mathrm{ONOO}^{-}$assay (table III), as the reduction of the 3-NT formation was significantly higher when Panaia-red pomace was used as an antioxidant agent.

Similar behaviour was recorded when the apple juice was examined, showing that Panaia-red had a higher capacity than Golden Delicious to scavenge both radicals. Immediately after production, the ability to reduce the 3-NT formation by the juice obtained from the local variety was around 9 times higher than that obtained from the commercial variety (table III). In relation to DPPH inhibition, we found the difference between the two juices to be smaller after 120 min of reaction. Panaiared juice's antioxidant capacity was 3 times higher than that of Golden delicious juice (table III). After 2 weeks storage in different temperature conditions, Panaia-red juice maintained its supremacy as an antioxidant agent towards both radicals, but during the DPPH• inhibition reaction the two varieties had different behaviour (table III). Analysing the coefficients $a$ and $b$ of the logarithmic curves, Panaia-red apple juice stored at $+4{ }^{\circ} \mathrm{C}$ was the most active for the first $30 \mathrm{~min}$ of reaction. Subsequently, the juice stored at RT after pasteurisation became the one with the highest reduction power. The juice stored at
$-20{ }^{\circ} \mathrm{C}$ was the least active throughout the reaction time. In the case of Golden Delicious, the juice stored at RT after pasteurisation was the most active during the entire reaction course, followed by the one stored at $-20{ }^{\circ} \mathrm{C}$. In this case, the juice with the lowest activity was the one stored at $+4{ }^{\circ} \mathrm{C}$ (table III). However, after 120 minutes of reaction, analysing the reduction carried out by the two juices immediately after production, Panaia-red juice reduction was $62 \%$ higher than that produced by Golden Delicious juice. Moreover, the reduction carried out by Panaia-red juice stored at RT after pasteurisation was $54 \%$ higher (table III). Further, for both the apple juices, after 120 min of reaction the cultivar was the only statistically significant parameter and the three storage conditions investigated were found not to be statistically different. The same performance can be described for the $\mathrm{ONOO}^{-}$assay of the samples stored for 2 weeks: in fact, also in this case, the juices stored at RT after pasteurisation were the ones with the highest values. Despite the performance and the dissimilarities recorded, no statistical differences were found among treatments and only the cultivar effect was found to be significant. Moreover, the Panaia-red juice stored at $+4{ }^{\circ} \mathrm{C}$ had higher values than the one stored at $-20^{\circ} \mathrm{C}$, whereas the Golden Delicious juice stored at $+4{ }^{\circ} \mathrm{C}$ had lower values than the one stored at $-20{ }^{\circ} \mathrm{C}$ (table III).

\subsection{Correlation}

As reported in our previous work [37], the antioxidant activity of apple fruits was principally correlated with phenolics concentration. In fact, TP and TF were reported to have a significant and positive correlation with the $\mathrm{ONOO}^{-}$scavenging capacity of the apple extracts $(r=0.83$ and $r=0.79$, respectively). Also, the correlation with DPPH• antiradical activity was found to be statistically significant, even if at lower levels. The correlation between antioxidant activity and physicochemical parameters was generally low or not significant, allowing us to suppose that the physicochemical traits were not influencing factors for the phenolic concentration and, consequently, for the antioxidant activity of the apple fruit [37].

The correlation analysis applied to the apple juice confirmed the significant and positive correlation between phenolic concentration and antioxidant activity (table $I V$ ), already reported in whole fruit [37]. As regards the Golden Delicious juice, all the three classes of phenolic compounds exhibited a highly significant correlation with the antioxidant capacity to scavenge the DPPH• and the F3Os were also found to highly correlate with the $\mathrm{ONOO}^{-}$. TP and TF had a lower correlation with $\mathrm{ONOO}^{-}$. Panaia-red apple juice was, instead, found to have a stronger correlation with $\mathrm{ONOO}^{-}$(table IV).

\subsection{Apple juice polyphenols concentration by HPLC}

The phenolic profile of the apple juice was investigated by HPLC analysis. Catechin, epicatechin, chlorogenic acid, phloretin, phloridzin and quercetin-3-galactoside, six of the major phenolic compounds of apple juices, were identified. The HPLC pattern was similar in the juices of Panaia-red 
Table III. Antioxidant activity measured by $\mathrm{ONOO}^{-}$-mediated tyrosine nitration and DPPH assays of apple pomace, apple juice after production, and apple juice after 2 weeks storage at $+4{ }^{\circ} \mathrm{C},-20{ }^{\circ} \mathrm{C}$ or at room temperature after pasteurisation (RT). Data were analysed by $t$-test for apple juice after preparation and by ANOVA for apple juice after 2 weeks storage.

\begin{tabular}{|c|c|c|c|c|c|}
\hline & $\begin{array}{c}\mathrm{ONOO}^{-} \\
\left(\mathrm{TE} \mathrm{g}^{-1} \mathrm{DM}^{\left.\text {or } \mathrm{L}^{-1}\right)}\right.\end{array}$ & $\begin{array}{c}\mathrm{DPPH}^{\mathrm{f}} \\
(\%)\end{array}$ & $\mathrm{a}^{\mathrm{g}}$ & $\mathrm{b}^{\mathrm{g}}$ & $r^{\mathrm{h}}$ \\
\hline \multicolumn{6}{|l|}{ Apple pomace } \\
\hline Golden Delicious & $1.58 \pm 0.01$ & $43.16 \pm 5.15$ & 7.62 & 5.66 & 0.984 \\
\hline Panaia-red & $2.47 \pm 0.18$ & $77.44 \pm 9.92$ & 17.01 & -4.38 & 0.997 \\
\hline$P$ values ${ }^{b}$ & $*$ & $* * *$ & $* * *$ & $*$ & \\
\hline \multicolumn{6}{|l|}{ Apple juice after preparation } \\
\hline Golden Delicious & $70.26 \pm 6.99$ & $33.83 \pm 9.53$ & 7.61 & -2.77 & 0.999 \\
\hline Panaia-red & $620.07 \pm 137.81$ & $89.51 \pm 3.88$ & 15.82 & 9.7 & 0.916 \\
\hline$P$ values ${ }^{\mathrm{b}}$ & $* * *$ & $* * *$ & $* * *$ & ns & \\
\hline \multicolumn{6}{|l|}{ Apple juice after 2 weeks storage } \\
\hline Golden Delicious $+4{ }^{\circ} \mathrm{C}$ & $47.93 \pm 7.12$ & $20.42 \pm 5.80$ & 4.36 & -0.95 & 0.995 \\
\hline Golden Delicious $-20^{\circ} \mathrm{C}$ & $64.81 \pm 14.72$ & $27.47 \pm 8.02$ & 5.31 & 1.67 & 0.998 \\
\hline Golden Delicious RT ${ }^{\mathrm{a}}$ & $125.36 \pm 49.11$ & $38.85 \pm 9.17$ & 7.66 & 1.82 & 0.998 \\
\hline Panaia-red $+4{ }^{\circ} \mathrm{C}$ & $524.44 \pm 198.17$ & $82.74 \pm 9.88$ & 14.29 & 11.76 & 0.969 \\
\hline Panaia-red $-20{ }^{\circ} \mathrm{C}$ & $496.43 \pm 229.41$ & $75.48 \pm 16.58$ & 15.99 & -1.22 & 0.997 \\
\hline Panaia-red $\mathrm{RT}^{\mathrm{a}}$ & $576.08 \pm 197.87$ & $84.17 \pm 9.18$ & 17.30 & 1.33 & 0.969 \\
\hline \multicolumn{6}{|l|}{$P$ ANOVA $^{\mathrm{b}}$} \\
\hline Cultivar & $* * *$ & $* * *$ & $* * *$ & ns & \\
\hline Temperature & ns & ns & $*$ & ns & \\
\hline Cultivar $\times$ Temperature & ns & ns & ns & ns & \\
\hline
\end{tabular}

${ }^{a}$ Room temperature after pasteurisation.

${ }^{\mathrm{b}}$ Mean differences significant at $* P \leqslant 0.05$, $* * P \leqslant 0.01$, *** $P \leqslant 0.001$; ns: not significant.

${ }^{\mathrm{f}}$ DPPH Percentage reduction measured after $120 \mathrm{~min}$ of reaction.

$\mathrm{g} \mathrm{a}$ and $\mathrm{b}$ are the coefficients of the logarithmic regression $[y=\mathrm{a} \ln (x)+\mathrm{b}]$ on the DPPH• reduction kinetics, calculated as means of 3 replicates.

${ }^{\mathrm{h}} r$ is the correlation coefficient of the regression curves.

Table IV. Correlation coefficient $(r)$ and $P$ values of the linear regression between phenolic concentration and antioxidant activity of Golden Delicious and Panaia-red apple juice $(* P<0.05$, ** $P<0.01$, *** $P<0.001)$.

\begin{tabular}{|c|c|c|c|c|c|c|c|c|}
\hline \multirow[b]{4}{*}{ Total phenolics } & \multicolumn{4}{|c|}{ Golden Delicious } & \multicolumn{4}{|c|}{ Panaia-red } \\
\hline & \multicolumn{2}{|c|}{ DPPH } & \multicolumn{2}{|c|}{$\mathrm{ONOO}^{-}$} & \multicolumn{2}{|c|}{ DPPH' } & \multicolumn{2}{|c|}{$\mathrm{ONOO}^{-}$} \\
\hline & $r$ & $P$ & $r$ & $P$ & $r$ & $P$ & $r$ & $P$ \\
\hline & 0.958 & *** & 0.689 & $*$ & 0.814 & $* *$ & 0.971 & *** \\
\hline Total flavonoids & 0.970 & $* * *$ & 0.701 & $*$ & 0.765 & $* *$ & 0.929 & $* * *$ \\
\hline Flavan-3-ols & 0.890 & $* * *$ & 0.857 & $* * *$ & 0.686 & $*$ & 0.816 & $* *$ \\
\hline
\end{tabular}

and Golden Delicious (table V). The most concentrated compound was epicatechin, followed by chlorogenic acid, catechin, phloridzin, phloretin and quercetin-3-galactoside in Panaia-red juices. Regarding Golden Delicious juices, the order was the same except for the last two compounds, quercetin3-galactoside being more concentrated than phloretin. The effect of variety was evident for most phenolics. Analysing juices immediately after production, Panaia-red juices had the highest value of chlorogenic acid, phloretin, phloridzin and quercetin-3-galactoside, whereas no statistically significant differences were observed in catechin and epicatechin concentrations (table V). Moreover, the phenolic concentration of Panaia-red and Golden Delicious juices after production was higher than in juices produced by Red Delicious, McIntosh and Spartan, especially for catechin, epicatechin and quercetin-3-galactoside [43].
Without pasteurisation, different storage temperatures were shown to decrease the concentrations of catechin and phlorizin in juices (table $V$ ). Pasteurisation and room temperature storage were the best way to preserve the phenolic content of juices, while the worst was conservation at $+4{ }^{\circ} \mathrm{C}$ for phloridzin and at $+4{ }^{\circ} \mathrm{C}$ and $-20{ }^{\circ} \mathrm{C}$ for catechin. Specifically, in Golden Delicious juice, catechin concentration at $+4{ }^{\circ} \mathrm{C}$ and phloretin concentration at $-20{ }^{\circ} \mathrm{C}$ were completely absent. In pasteurised juice, the catechin amount increased by $42 \%$ with respect to juice after preparation and decreased in juices stored at $-20{ }^{\circ} \mathrm{C}$ by $31 \%$, whereas phloridzin concentration increased by $29 \%$ in pasteurised juice, decreased by $32 \%$ in juice stored at $+4{ }^{\circ} \mathrm{C}$ and was similar in juice stored at $-20{ }^{\circ} \mathrm{C}$. In pasteurised Panaia-red juice, the catechin concentration increased by $13 \%$ with respect to juice after preparation, whereas in juices stored at $+4{ }^{\circ} \mathrm{C}$ and $-20{ }^{\circ} \mathrm{C}$ the concentration was similar 
Table V. Catechin, epicatechin, chlorogenic acid, phloretin, phloridzin and quercetin-3-galactoside concentrations of Golden Delicious and Panaia-red apple juice after production and after 2 weeks storage at $+4{ }^{\circ} \mathrm{C},-20{ }^{\circ} \mathrm{C}$ or at room temperature after pasteurisation (RT). Data were analysed by $t$-test for apple juice after preparation and by ANOVA for apple juice after 2 weeks storage. Values are the means \pm SD $(n=3)$.

\begin{tabular}{|c|c|c|c|c|c|c|}
\hline & \multicolumn{6}{|c|}{ Phenolics content $\left(\mathrm{mg} \mathrm{L}^{-1}\right)$} \\
\hline Apple juice after preparation & Catechin & Epicatechin & Chlorogenic acid & Phloretin & Phloridzin & Querc-3-galactoside \\
\hline Golden Delicious & $89.1 \pm 35.0$ & $144.4 \pm 41.7$ & $103.9 \pm 25.8$ & $1.8 \pm 0.3$ & $31.1 \pm 6.1$ & $5.9 \pm 1.4$ \\
\hline Panaia-red & $148.6 \pm 53.2$ & $473.2 \pm 263.8$ & $166.2 \pm 18.0$ & $52.9 \pm 12.4$ & $116.0 \pm 8.5$ & $22.15 \pm 6.0$ \\
\hline$P$ values & $\mathrm{ns}$ & $\mathrm{ns}$ & $*$ & $* *$ & $*$ & $* * *$ \\
\hline \multicolumn{7}{|c|}{ Apple juice after 2 weeks storage } \\
\hline Golden Delicious $+4{ }^{\circ} \mathrm{C}$ & 0 & $79.4 \pm 23.4$ & $74.8 \pm 25.2$ & $1.6 \pm 0.2$ & $21.1 \pm 5.0$ & $4.3 \pm 1.2$ \\
\hline Golden Delicious $-20^{\circ} \mathrm{C}$ & $61.4 \pm 25.0$ & $116.2 \pm 41.1$ & $92.7 \pm 27.7$ & 0 & $33.0 \pm 7.5$ & $5.4 \pm 1.2$ \\
\hline Golden Delicious RT ${ }^{\mathrm{a}}$ & $153.8 \pm 49.5$ & $165.0 \pm 50.4$ & $117.3 \pm 25.7$ & $1.9 \pm 0.2$ & $43.8 \pm 9.4$ & $6.3 \pm 1.6$ \\
\hline Panaia-red $+4{ }^{\circ} \mathrm{C}$ & $148.8 \pm 43.1$ & $474.5 \pm 172.0$ & $154.7 \pm 20.0$ & $47.9 \pm 12.0$ & $110.9 \pm 7.8$ & $23.8 \pm 6.4$ \\
\hline Panaia-red $-20^{\circ} \mathrm{C}$ & $152.9 \pm 41.7$ & $529.9 \pm 202.5$ & $158.8 \pm 21.3$ & $51.3 \pm 12.1$ & $113.9 \pm 8.2$ & $25.4 \pm 8.4$ \\
\hline 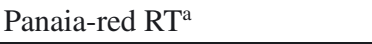 & $171.0 \pm 60.1$ & $572.7 \pm 260.0$ & $165.7 \pm 23.3$ & $53.5 \pm 12.8$ & $116.8 \pm 8.7$ & $21.6 \pm 5.1$ \\
\hline \multicolumn{7}{|l|}{$P$ ANOVA } \\
\hline Cultivar & $* * *$ & *** & $* * *$ & $* * *$ & $* * *$ & $* * *$ \\
\hline Temperature & $* *$ & ns & ns & ns & $*$ & ns \\
\hline Cultivar $\times$ Temperature & ns & $\mathrm{ns}$ & ns & ns & ns & ns \\
\hline
\end{tabular}

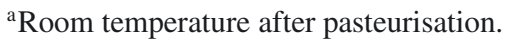

${ }^{\mathrm{b}}$ Mean differences significant at $* P \leqslant 0.05, * * P \leqslant 0.01, * * * P \leqslant 0.001$; ns: not significant.

to the juice after preparation (table $V$ ). Kahle et al. [14] analysed the phenolics concentration of 4 dessert apple juices (Red Delicious, Golden Delicious, Granny Smith and Fuji) and 7 German cider apple juices immediately after preparation. In comparison with our results for Golden Delicious juice, they found lower values for all the phenolic compounds analysed. They also measured the phenolics concentration of 21 commercial cloudy apple juices. The concentrations of phenolic compounds measured in our Panaia-red and Golden Delicious pasteurised juices were much higher than in the commercial ones, except for chlorogenic acid [14]. Golden Delicious and Panaia-red juices had higher concentrations of catechin and epicatechin than some French (Ariane, Chanteline, Judeline and Judor) and Polish varieties (Ariwa, Florina, Gold Milenium, Melfree, Novamac and Rajka), and, except for Judor, also of phloridzin. On the contrary, chlorogenic acid concentrations were higher in Ariwa, Gold Milenium and Melfree juices compared with Panaia-red and Golden Delicious [46].

Catechin is a good substrate of PPO in the presence of oxygen, and PPO is inactivated by pasteurisation [43]. These two complementary effects could have preserved the catechin content of our juices. Moreover, an additional extraction of catechins from the solid phase of the juice residues and depolymerisation of complex structures (such as procyanidins) to simpler compounds (catechin and epicatechin monomers) could have happened.

\section{Conclusion}

Apple juice and pomace can be considered as good and easily accessible sources for nutraceutical compounds. A higher level of phenolic concentration and antioxidant capacity were observed in the juice obtained from the typical ancient Tuscan variety, Panaia-red, with respect to the commer- cial variety, Golden Delicious. Even after two weeks storage, Panaia-red apple juice maintained a higher level of phenolic compounds. Antioxidant activity of apple juice and pomace was investigated by means of the peroxynitrite-induced tyrosine nitration test, more representative of human physiological conditions than other antiradical assays. A desirable level of correlation between antioxidant activity and phenolic concentration was observed. In addition, the high concentration of phenolic compounds and the high antioxidant activity of Panaia-red apple juice highlight the potential of this ancient variety for marketable products with a larger range of distribution, despite a lower yield. No treatments with pectolytic enzymes were added to increase juice yield. For that reason, it is important to focus the attention on apple pomace, a byproduct of juice production that revealed a significant amount of phenolics. This paves the way for their use as ingredients in foods lacking in polyphenols or to supply juices with additional polyphenols.

In general, phenolic concentrations and antioxidant activity remained quite stable in both varieties during storage. In addition, our analysis showed that the best way to preserve polyphenols in juice was pasteurisation followed by storage at room temperature. However, it should be remembered that the effect of antioxidant compounds on human health is largely dependent on their bioavailability and not only on their concentration in food.

Acknowledgements. The present work was supported by funds of Regione Toscana, as part of the project "Caratterizzazione $e$ valorizzazione economica del patrimonio frutticolo autoctono del Casentino", and by funds of the University of Pisa and Sant'Anna University. The authors are grateful to Gaia Monteforti for help given during apple juice preparation and Janeen Achtar for reviewing the English and grammar. 


\section{References}

[1] Cook N.C., Samman S., Flavonoids - Chemistry, metabolism, cardioprotective effects, and dietary sources, J. Nutr. Biochem. 7 (1996) 66-76.

[2] Harborne J.B., Williams C.A., Advances in flavonoid research since 1992, Phytochemistry 55 (2000) 481-504.

[3] Heim K.E., Tagliaferro A.R., Bobilya D.J., Flavonoid antioxidants: chemistry, metabolism and structure-activity relationship, J. Nutr. Biochem. 13 (2002) 572-584.

[4] Dillard C.J., German J.B., Phytochemicals: nutraceuticals and human health, J. Sci. Food Agric. 8012 (2000) 1744-1756

[5] Tsao R., Yang R., Optimization of a new mobile phase to know the complex and real polyphenolic composition: towards a total phenolic index using high-performance liquid chromatography, J. Chromatog. A 1018 (2003) 29-40.

[6] Diñeiro García, Y, Suárez Valles, B, Picinelli Lobo, A., Phenolic and antioxidant composition of by-products from the cider industry: Apple pomace, Food Chem. 117 (2003) 731-738.

[7] Jakopic J., Slatnar A., Stampar F., Veberic R., Simoncic A., Analysis of selected primary metabolites and phenolic profile of 'Golden Delicious' apples from four production systems, Fruits 67 (2012) 377-386.

[8] Tsao R., Yang R., Xie S., Sockovie E., Khanizadeh S., Which polyphenolic compounds contribute to the total antioxidant activities of apple? J. Agric. Food Chem. 53 (2005) 4989-4995.

[9] Napolitano A., Cascone A., Graziani G., Ferracane R., Scalfi L., Di Vaio C., Ritieni A., Fogliano V., Influence of variety and storage on the polyphenol composition of apple flesh, J. Agric. Food Chem. 52 (2004) 6526-6531.

[10] Manach C., Williamson G., Morand C., Scalbert A., Remesy C., Bioavailability and bioefficacy of polyphenols in humans. I. Review of 97 bioavailability studies, Am. J. Clin. Nutr., (2005) 230S-242S.

[11] Guyot S., Marnet N., Sanoner P., Drilleau J.F., Variability of the polyphenolic composition of cider apple (Malus domestica) fruits and juices, J. Agric. Food Chem. 51 (2003) 6240-6247.

[12] Van der Sluis A.A., Dekker M., Skrede G., Jongen W.M.F., Activity and concentration of polyphenolic antioxidants in apple juice. 1. Effect of existing production methods, J. Agric. Food Chem. 50 (2002) 7211-7219.

[13] Barth S.W., Fahndrich C., Bub A., Dietrich H., Wartz B., Will F., Briviba K., Rechkemmer G., Cloudy apple juice decreases DNA damage, hyperproliferation and aberrant crypt foci development in the distal colon of DMH-inhibited rats, Carcinogenesis, 26 (2005) 1414-1421.

[14] Kahle K., Kraus M., Richling E., Polyphenol profiles of apple juices, Mol. Nutr. Food Res. 49 (2005) 797-806.

[15] Markowski J., Kolodziejczyk K., Krol B., Plocharski W., Rutkowski K., Phenolic in apples and processed apple products, Polish J. Food Nutr. Sci. 57 (2007) 383-388.

[16] Murata M., Tsurutani M., Hagiwara S, Homma S., Subcellular location of polyphenol oxidase in apples, Biosci. Biotechnol. Biochem. 61 (1997) 1495-1499.

[17] Will F., Schulz K., Ludwig M., Otto K., Dietrich H., The influence of enzymatic treatment of mash on the analytical composition of apple juice, Int. J. Food Sci. Technol. 37 (2002) 653-660.

[18] Gliszczynska-Swiglo A., Tyrakowska B., Quality of commercial apple juices evaluated on the basis of the polyphenol content and the TEAC antioxidant activity, J. Food Sci. 68 (2003) 1844-1849.
[19] Markowski J., Mieszczakowska M., Płocharski W., Effect of apple cultivar and enzyme treatment on phenolic compounds content during clear apple juice production, Int. J. Food Sci. Technol. 44 (2009) 1002-1010.

[20] Miller N.J., Diplock A.T., Rice-Evans C.A., Evaluation of the total antioxidant activity as a marker of the deterioration of apple juice on storage, J. Agric. Food Chem. 43 (1995) 17941801.

[21] Miller N.J., Rice-Evans C.A., The relative contributions of ascorbic acid and phenolic antioxidants to the total antioxidant activity of orange and apple fruit juices and blackcurrant drink, Food Chem. 60, 3 (1997) 331-337.

[22] Boyer J., Liu R.H., Apple phytochemicals and their health benefits. Nutr. J. 3 (2004) 1-15.

[23] Serra A.T., Rocha J., Sepodes B., Matias A.A., Feliciano R.P., de Carvalho A., Bronze M.R., Duarte C.M.M., Figueira M.E., Evaluation of cardiovascular protective effect of different apple varieties- Correlation of response with composition, Food Chem. 135 (2012) 2378-2386.

[24] Gerhauser C., Cancer chemopreventive potential of apples, apple juice, and apple components, Planta Med. 74 (2008) 16081624.

[25] Dai Q., Borenstein A.R., Wu Y., Jackson J.C., Larson E.B., Fruit and vegetable juices and Alzheimer's disease: The Kame Project. Am. J. Med. 119 (2006) 751-759.

[26] Hang Y.D., Woodams E.E., Apple pomace: a potential substrate for citric acid production by Aspergillus niger, Biotechnol. Lett. 6 (1984) 763-764.

[27] Vendruscolo F., Albuquerque P.M., Streit F., Esposito E., Ninow J.L., Apple pomace: a versatile substrate for biotechnological applications, Crit. Rev. Biotechnol. 28 (2008) 1-12.

[28] Makris D.P., Boskou G., Andrikopoulos N.K., Recovery of antioxidant phenolics from white vinification solid by-products employing water/ethanol mixtures, Bioresource Technol. 98 (2007) 2963-2967.

[29] Van der Sluis A.A., A chain analysis of the production of 'healthy' apple juice. The case of polyphenolic antioxidants. PhD Thesis, Wageningen University, The Netherlands, 2005.

[30] Gallesio G., Pomona Italiana, ossia trattato degli alberi da frutto, N. Capurro, Pisa (1817-1839).

[31] VV.AA., Alla riscoperta della frutta antica del Casentino. Un patrimonio agroalimentare di alto pregio genetico, culturale ed economico, edited by Camangi F., Stefani A., Segantini L., Seravelli M. Edizioni ETS, Pisa (2013).

[32] VV.AA., Conservation of and Adding of Value to the Patrimony of local Breeds and Varieties Tuscany. Regione Toscana (2010).

[33] Singleton V.L., Rossi J.A.J., Colorimetry of total phenolics with phosphomolybdic-phosphotungstic acid reagents, Am. J. Enol. Vitic. 16 (1965) 144-158.

[34] Kim H.Y., Kang M.H., Flavonoid content of some Korean medicinal plants, Food Sci. Biotechnol. 12 (2003) 687-690.

[35] Nagel C.W., Glories Y., Use of a modified dimethylaminocinnamaldehyde reagent for analysis of flavanols. Am. J. Enol. Vitic. 42 (1991) 364-366.

[36] Beckman J.S., Chen J., Ischiropoulos H., Crow J.P., Oxidative chemistry of peroxynitrite. Meth. Enzymol. 233 (1994) 229240.

[37] Iacopini P., Camangi F., Stefani A., Sebastiani L., Antiradical potential of ancient Italian apple varieties of Malus $\times$ domestica Borkh. in a peroxynitrite-induced oxidative process, J. Food Comp. Anal. 23 (2010) 518-524. 
[38] Brand-Williams, W, Cuvelier, ME, Berset, C. Use of a free radical method to evaluate antioxidant activity. Food Sci. Technol. 28 (1995) 25-30.

[39] Aguilar-Rosas S.F., Ballinas-Casarrubias M.L., NevarezMoorillon G.V., Martin-Belloso O., Ortega-Rivas E., Thermal and pulsed electric fields pasteurization of apple juice: Effects on physicochemical properties and flavour compounds, J. Food Engin. 83 (2007) 41-46.

[40] Sanchez-Moreno C., Plaza L., de Ancos B., Cano M.P., Quantitative bioactive compounds assessment and their relative contribution to the antioxidant capacity of commercial orange juices, J. Sci. Food Agric. 83 (2003) 430-439.

[41] Ćetković G., Čanadanović-Brunet J., Djilas S., Savatoviæ S., Mandiæ A., Tumbas V., Assessment of polyphenolic content and in vitro antiradical characteristics of apple pomace, Food Chem. 109 (2008) 340-347.
[42] Suarez B., Álvarez Á.L., Diñeiro García Y., del Barrio G., Picinelli Lobo A., Parra F., Phenolic profiles, antioxidant activity and in vitro antiviral properties of apple pomace, Food Chem. 120 (2010) 339-342.

[43] Spanos G.A., Wrolstad R.E., Heatherbell D.A., Influence of processing and storage on the phenolic composition of apple juice, J. Agricult. Food Chem. 38 (1990) 1572-1579.

[44] Hertog M.G.L., Hollman P.C.H., Katan M.B., Content of potentially anticarcinogenic flavonoids of 28 vegetables and 9 fruits commonly consumed in the Netherlands, J. Agric. Food Chem. 40 (1992) 2379-2383.

[45] Hertog M.G.L., Hollman P.C.H., van de Putte B., Content of potentially anticarcinogenic flavonoids of tea infusions, wines, and fruit juices J. Agric. Food Chem. 41 (1993) 1242-1246.

[46] Markowski J., Baron A., Mieszczakowaka M., Plocharski W., Chemical composition of French and polish cloudy apple juices. J. Hortic. Sci. Biotechnol. (2009) 68-74.

Cite this article as: Esther Maragò, Patrizia Iacopini, Fabiano Camangi, Claudia Scattino, Annamaria Ranieri, Agostino Stefani, Luca Sebastiani. Phenolic profile and antioxidant activity in apple juice and pomace: effects of different storage conditions. Fruits 70 (2015) 213-223. 